

\title{
AVALIAÇÃO DA CIRCULAÇÃO EM SALAS DE AULA UNIVERSITÁRIAS: UM ESTUDO DE CASO UTILIZANDO O MACHIA
}

\author{
BARROS, Bruno Xavier da Silva (1)
}

(1) Universidade Federal de Pernambuco, Mestre

e-mail: barros bruno@hotmail.com

\begin{abstract}
RESUMO
A circulação horizontal de um ambiente voltado para o ensino é extremamente importante, sua qualidade pode favorecer a disseminação de conteúdos, promovendo a concentração, ou dificultar a transmissão e assimilação do conhecimento, através de interrupções constantes. Nas salas de aula do curso de Design da UFPE/CAA, se observou que os alunos caminham lentamente entre carteiras, se esquivando dos cadernos e braços de estudantes que fazem anotações. No intuito de verificar a relação entre a dimensão da sala e a quantidade de carteiras disponibilizadas, lançamos mão do método MACHIA para avaliar e propor soluções antropométricas para a circulação do ambiente.
\end{abstract}

Palavras chave: sala de aula; circulação horizontal; MACHIA.

\begin{abstract}
The horizontal circulation of a environment directed for education is extremely important, their quality can promote the dissemination of content, providing concentration, or hinder the transmission and assimilation of knowledge through constant interruptions. In the course of classrooms Design UFPE / $C A A$, it was observed that students walk slowly between desks, dodging notebooks and arms of students who are taking notes. In order to verify the relationship between the size of the classroom and the amount of available desks, we used the Machia method to evaluate and propose anthropometric solutions to the environmental circulation.
\end{abstract}

Keywords: classroom; horizontal circulation; MACHIA.

\section{INTRODUÇÃO}

O Centro Acadêmico do Agreste (CAA) é o primeiro campus da UFPE no interior do estado de Pernambuco, tendo sido inaugurado em março de 2006, com o objetivo de contribuir com o desenvolvimento social, econômico e cultural do Estado. O Centro Acadêmico do Agreste iniciou suas atividades com cinco graduações, dentre elas, o curso de graduação em Design. As salas de aula do curso de design são compostas por carteiras (direcionadas para aulas teóricas) ou pranchetas (voltadas para conteúdos práticos). As dimensões das salas são de $35 \mathrm{~m}^{2}$ ou $70 \mathrm{~m}^{2}$ e sua capacidade chega a 40 alunos (disciplinas obrigatórias).

O leiaute interno de qualquer sala de aula deve permitir o melhor desempenho da atividade de professores e alunos. $O$ ato de olhar para a lousa, circular entre as carteiras e ministrar aula demandam um leiaute adequado e espaços de circulação permissível. Inadequações deste sentido prejudicam o andamento natural da aula, dificultando a concentração e o raciocínio de alunos e professores. Dentro deste contexto encontram-se as salas de aula do 




curso de Design/CAA, as quais, devido à necessidade de comportar até quarenta alunos, a quantidade de carteiras presentes em sala impede que se modifique o leiaute de acordo com algum tipo de dinâmica diferenciada de aula que se deseje ministrar.

São disponibilizadas 40 carteiras em cada sala de aula, contudo, no caso de disciplinas obrigatórias, alunos que reprovaram ou trancaram o curso matriculam-se novamente nas disciplinas, excedendo o quantitativo máximo de carteiras (inserindo mais carteiras no ambiente). Deste modo, se observam alunos caminhando lentamente e com bastante cuidado em corredores estreitos formado por carteiras muito próximas entre si, prejudicando a concentração de alunos e professores, bem como pondo alguns materiais de grande valor (como o caso de notebooks) em risco de queda.

Esta situação cotidiana vivenciada por alunos e professores do curso de Design estimulou a realização da referente pesquisa, a qual teve como objetivo a análise da circulação horizontal interna do modelo de sala de aula com carteiras e capacidade para 40 alunos. Para tanto, lançou-se mão do método MACHIA, o qual realiza uma classificação cromática de situações antropométricas permissíveis; de risco; e inadequadas da circulação.

\section{FUNDAMENTAÇÃO TEÓRICA}

Em uma sala de aula o professor controla os meios, processos e didática, bem como organiza a sala de acordo com a atividade e o objetivo a serem atingidos, deste modo, a sala de aula deve adequar-se aos objetivos propostos pelo professor. Existem diversos tipos de arranjo físico adotados por professores referentes ao mobiliário e disposição dos alunos em salas de aula, encontramos em Carvalho (2005, p. 18) a seguinte tipificação geral: 1. Em filas e colunas (mais tradicionais, onde as informações são centralizadas no professor e a discussão não ocorre entre os participantes, mas entre participantes e professor); 2. Em filas horizontais (muito útil para demonstrações, em função da proximidade professor/aluno. Esses arranjos não são indicados para provocar discussão e atividades em grupo); 3 . Em círculo (contraindicado para apresentações ou demonstrações porque alguns alunos ficarão atrás do professor); 4. Em semicírculo (favorece a discussão); 5 . Em grupo (útil para a discussão e aprendizagem cooperativa), podem ser formados por grupos de quatro e de seis alunos, com arranjo para aprendizagem cooperativa e com arranjo frontal. (CARVALHO, 2005, p. 18).

Identificamos estudos formais a respeito dos arranjos físicos de sala de aula, assim como suas tipificações de densidade, conforto e desempenho escolar, datados de quase trinta anos, como é o caso de Rosenfield, Lambert e Black (1985); Arends (2008); Pucci (2001). Os autores defendem que o leiaute do espaço educacional (dimensão, acústica, densidade populacional e disposição do mobiliário) somado à metodologia de ensino, exerce grande influência no comportamento dos alunos. Estes, por sua vez, interagem a partir de suas particularidades e atitudes na organização social desse ambiente.

Boueri Filho (2009), explica que a maioria dos problemas encontrados nos ambientes está relacionada com a não utilização de medidas humanas nos projetos. Para Villarouco (2007), os espaços necessitam atender a critérios antropométricos, de conforto do ambiente e questões referentes à percepção e sensação dos usuários. Neste sentido, Panero e Zelnik (2013) os dados relacionados ao projeto de ambientes internos são aplicados sob a forma de padrões referenciais, de modo a garantir que as pessoas sejam satisfeitas adequadamente pelos vários componentes dos ambientes internos em que vivem.

Panero e Zelnik (2013), afirmam que a circulação deve ser definida para satisfazer uma pessoa de dimensões grandes, pois assim ela irá atender uma maior quantidade de usuários. Os autores consideram dois tipos de circulação: uma chamada de Circulação Horizontal e outra chamada de Circulação Vertical. A circulação horizontal considera as 




medidas vistas de cima (planta baixa) ou como o próprio nome diz as medidas horizontais, já a circulação vertical considera as medidas verticais em uma visão lateral.

Para o espaço de sala de aula, uma dimensão mínima se faz necessária no intuito de se permitir uma circulação adequada. Esta dimensão é diretamente afetada pela área da sala, pela quantidade de mobiliário disposto e pela quantidade de pessoas no local. Neste sentido, encontramos no Código de Urbanismo, Obras e Posturas do Município de Caruaru (Lei 2454.77), cidade onde se localiza o estudo de caso desta pesquisa, a determinação do Art. 394, o qual indica que as salas de aula devem dispor de área mínima de quarenta metros quadrados $\left(40 \mathrm{~m}^{2}\right)$. Este artigo também prescreve que uma sala de aula comum deve oferecer uma área equivalente à 1,2 a $1,5 \mathrm{~m}^{2}$ por aluno. $\mathrm{O}$ estudo de caso desta pesquisa (Curso de Design da UFPE/CAA) também é regido pelo Plano Diretor Físico vigente na Universidade Federal de Pernambuco, o qual é datado de 1985. Em seu anexo 2 (Critérios para Dimensionamento de Edifícios no Campus), o Plano Diretor determina que a dimensão das salas de aula devem ser quantificadas pela razão de 1 a $1,3 \mathrm{~m}^{2}$ por aluno.

\section{METODOLOGIA}

O Método de Avaliação da Circulação Horizontal Interna de Ambientes, sugerido por Barros (2009), propõe a realização de um diagnóstico cromático de acordo com cada situação encontrada no ambiente. O princípio do MACHIA é perceber os aspectos antropométricos avaliados através de pesquisas e, a partir de então, confrontá-los, através de uma simulação da circulação horizontal com a inserção de modelos antropométricos em plantas com layout de ambientação. No método são aplicados manequins antropométricos realizando uma simulação de circulação interna de um ambiente, classificados da seguinte forma: em verde, aparecem os manequins em situações em que estão adequadas para a circulação; em amarelo, os manequins que representam situações que merecem uma maior atenção, apresentando alguma situação de risco; e, em vermelho, os manequins em situações consideradas inadequadas. A figura 1, a seguir, apresenta a classificação dos modelos antropométricos definidos pelo método e suas dimensões físicas e de campo de circulação.

Figura 1: Modelos Antropométricos adotados pelo MACHIA.



Fonte: Barros e Seabra (2013). 




Por recomendação do MACHIA, utilizamos a planta baixa de uma das salas de aula do curso de Design, mantendo-se as escalas e proporções reais entre espaço e manequins antropométricos, buscando uma análise mais fiel à realidade. Na planta baixa foi disposto o layout e o mobiliário existente, onde foram inseridos os modelos antropométricos para verificar o espaço da circulação interna.

Os modelos antropométricos coloridos de verde foram locados em locais onde os ambientes apresentam mobilidade confortável para os usuários, os modelos em amarelo foram colocados onde a movimentação necessita de maior atenção, representando áreas de risco, já os modelos em vermelho apresentam os locais onde existem falhas no projeto, ocasionando situações inadequadas para os usuários. Barros (2009) afirma que se pode adotar como falhas ou erro no projeto, locais que, pela óptica da antropometria, não permitem a realização de atividades cotidianas, onde facilmente percebe-se que o entorno ultrapassa a linha limite de circulação individual dos modelos antropométricos na simulação do ambiente realizada em planta baixa.

Na realização da referente pesquisa também lançamos mão do método de Estudo de Caso por se caracterizar como um tipo de pesquisa cujo objeto é uma unidade que se analisa profundamente. Faz-se necessário ter em mente o fato de que o Método do Estudo de Caso "(...) não é uma técnica específica. É um meio de organizar dados sociais preservando o caráter unitário do objeto social estudado." (HAMMERSLEY et al. 2014, p.37). Neste sentido, Gerring (2006, p. 46) complementa afirmando que "um estudo de caso refere-se a uma análise intensiva de uma situação particular." A necessidade de um recorte na pesquisa para possibilitar uma análise de maior profundidade, conduziu o estudo para o norteamento por Estudo de Caso, o qual selecionou o modelo das salas de aula do curso de Design da UFPE/CAA.

\section{RESULTADOS}

Sobre a planta baixa do modelo de sala de aula com carteiras, foram sobrepostos os manequins antropométricos simulando a circulação. A planta baixa com a composição cromática da avaliação guiada pelo MACHIA pode ser acompanhada pela figura 2 a seguir:

Figura 2: Avaliação da circulação da sala de aula utilizando o MACHIA.



Fonte: Elaborado pelo autor para a pesquisa.

O método identificou inadequações de circulação e ainda trouxe à tona o fato do reduzido espaço em volta do birô, tanto para utilização por parte dos alunos quanto dos professores. 




Se considerarmos a necessidade de espaço direcionado a um cadeirante ou um muletante (como recomenda a NBR 9050:2015), a área possível disponível para fluxo na sala seria apenas entre a porta e as primeiras carteiras. A figura 3 a seguir, apresenta a simulação da circulação por um cadeirante no ambiente de sala de aula. Os manequins na cor vermelha indicam a impossibilidade de trânsito e os de cor verde, a circulação adequada.

\section{Figura 3: Fluxo de cadeirante na parte interna da sala.}



Fonte: Elaborado pelo autor para a pesquisa.

Como vimos no levantamento bibliográfico desta pesquisa, o Código de Urbanismo, Obras e Posturas do Município de Caruaru (Lei 2454.77) determina que as salas de aula devem ter área mínima de quarenta metros quadrados $\left(40 \mathrm{~m}^{2}\right)$ e que uma sala de aula comum deve possuir uma área equivalente à 1,2 a $1,5 \mathrm{~m}^{2}$ por aluno. Já o Plano Diretor Físico vigente na Universidade Federal de Pernambuco, determina que a dimensão das salas de aula devem ser quantificadas pela razão de 1 a $1,3 \mathrm{~m}^{2}$ por aluno. No entanto, as salas de aula investigadas possuem $35,00 \mathrm{~m}^{2}$. Sendo assim, ao considerarmos o mínimo de $1,2 \mathrm{~m}^{2}$ por aluno (mínimo permitido pelo Código de Urbanismo, Obras e Posturas de Caruaru) em uma sala de aula destinada a 40 alunos, seriam necessários $48 \mathrm{~m}^{2}$, o que revela uma diferença de $13 \mathrm{~m}^{2}$. Ao considerarmos o valor de $1 \mathrm{~m}^{2}$ por aluno (mínimo permitido pelo plano diretor da UFPE), seriam necessários $40 \mathrm{~m}^{2}$, revelando uma diferença de $5 \mathrm{~m}^{2}$ na sala de aula. Sob nenhum dos parâmetros reguladores de dimensão da sala de aula investigada é possível justificar a área de $35,00 \mathrm{~m}^{2}$ ou a inserção de 40 carteiras (ou mais) nesta área.

Haja vista este espaço reduzido, as carteiras são dispostas muito próximas entre si, tanto em sua face frontal e posterior, quanto nas laterais, comprometendo a circulação. Esta insuficiência de área livre interfere diretamente no espaço pessoal do indivíduo, o qual é violado pela exiguidade disponível nas salas. É válido alertar que a distância entre as pessoas indica o grau de intimidade entre elas, deste modo podemos inferir que o espaço físico das salas estaria impondo aos usuários uma intimidade não necessariamente requerida.

Também foi constatado que a proximidade frontal e posterior entre as carteiras impede a acomodação adequada dos membros inferiores dos alunos, a estrutura da carteira imediatamente à frente oferece riscos de lesão nos joelhos de alunos com estatura mais elevada, uma vez que comprime esta parte do corpo, elevando a inquietude do aluno no decorrer da aula. Esta proximidade também impede que o aluno acople a mochila na carteira da frente, fazendo com que este a apoie sobre as coxas, sobre outra carteira desocupada ou a disponha no chão da sala. Por falta de opção, alguns alunos optam por colocar no chão, reduzindo (ainda que minimamente) o desconforto, outros preferem apoiá- 




la sobre as coxas, uma vez que preferem não terem suas mochilas maculadas pela poeira do chão da sala.

Foi evidenciado, ainda, que esta mesma proximidade frontal prejudica o acesso às bancas da primeira fileira da direita (visão a partir da lousa). O limite frontal da prancheta da carteira fica rente com a parte posterior da carteira de frente, impedindo o acesso do aluno ao assento. Deste modo, o aluno se vê na necessidade de solicitar ajuda a todos os alunos da mesma fileira para que afastem suas carteiras e, com isso, se disponha de espaço para acesso ao assento. Esta prática interrompe a aula, atrapalha o raciocínio de alunos e professores e dispersa a turma, além de constranger o aluno que solicita o favor dos colegas.

A proximidade entre as carteiras também foi verificada em suas laterais, configurando corredores deveras estreitos em toda a sala. Para ter acesso a uma carteira, os alunos desviam de notebooks e materiais escolares dispostos sobre as pranchetas, acarretando o risco de queda de material e possível dano financeiro, bem como na interrupção da aula. Esta proximidade (somada à quantidade de carteiras por sala) também prejudica a circulação de cadeirantes em seu interior, impossibilitando que um aluno em cadeira de rodas participe da aula da melhor maneira possível. Além do notório risco de dano material decorrente da queda de equipamentos, o aluno se põe em uma situação constrangedora de solicitar a gentileza dos demais alunos do corredor no intuito de obter espaço para circular. O aluno pode vir a optar por evitar que esta situação se repita no decorrer da aula, mas ele teria que se ver na necessidade de abdicar da necessidade de ir ao banheiro (entre outras), acarretando e riscos mais graves à sua saúde.

Ficou claro o reduzido espaço permissível para a circulação de um cadeirante, o qual, ainda que se acomode apenas no primeiro espaço da sala, teria seu trajeto comprometido sempre que fosse necessário realizar uma atividade na lousa de ensino (tal como apresentação de trabalhos ou exercícios). Neste sentido, a aplicação do MACHIA permitiu a elaboração de uma série de requisitos dimensionais para adequação antropométrica da circulação da sala de aula, como exposto a seguir:

- Para as salas não acessíveis (no máximo duas para cada sala acessível - NBR 9050), o espaço de atividades do professor (compreendida entre a parte posterior do encosto da cadeira e a lousa) deve permitir a circulação com dimensão mínima de 0,65m; Deve-se considerar ainda a possibilidade de ampliação do número de salas acessíveis;

- A área compreendida entre a parte frontal do tampo da mesa do professor e as primeiras carteiras deve permitir circulação mínima para dois indivíduos, um de maneira frontal e outro de maneira lateral, com dimensão mínima de 1,05m;

Figura 4: Área de atividades do professor (sala não acessível).



Fonte: Elaborado pelo autor para pesquisa. 




- No caso de salas de aula com corredores laterais às carteiras, a distância lateral entre as carteiras devem ter a largura mínima de $0,65 \mathrm{~m}$, para permitir a circulação de alunos sem prejuízos ao andamento da aula;

Figura 5: Circulação entre fileiras de carteiras em sala de aula.
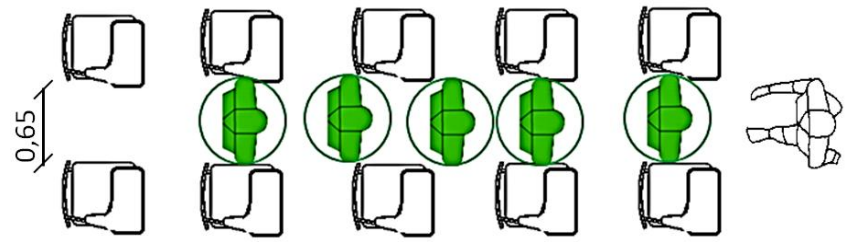

Fonte: Elaborado pelo autor para pesquisa.

- Salas de aula com corredores de circulação nas laterais das carteiras, devem apresentar um afastamento frontal e posterior de no mínimo de 0,40m para permitir um fácil e cômodo acesso;

Figura 6: Distância frontal/ posterior entre carteiras.



Fonte: Elaborado pelo autor para pesquisa.

- Ao se optar este tipo de leiaute de sala com corredores laterais às carteiras, levando-se em consideração os espaços de circulação, dimensões das carteiras e área do professor (além da necessidade de comportar 40 alunos), deve-se dispor de uma área mínima de $68,31 \mathrm{~m}^{2}$ de sala de aula (uma razão de $1,7 \mathrm{~m}^{2}$ por aluno);

- No caso de salas de aula com corredores frontais e posteriores às carteiras, a distância frontal e posterior entre estas carteiras deve ter a largura mínima de 0,65m, para permitir a circulação de alunos sem prejuízos ao andamento da aula;

Figura 7: Largura para corredores frontais/ posteriores às carteiras.



Fonte: Elaborado pelo autor para pesquisa. 




- As salas de aula com corredores de circulação frontal e posterior às carteiras, devem apresentar um afastamento lateral de no mínimo $0,40 \mathrm{~m}$ para permitir um fácil e cômodo acesso;

Figura 8: Largura para corredores laterais às carteiras.



Fonte: Elaborado pelo autor para pesquisa.

- Ao se optar este tipo de leiaute de sala com corredores frontais e posteriores às carteiras, levando-se em consideração os espaços de circulação, dimensões das carteiras e área do professor (além da necessidade de comportar 40 alunos), deve-se dispor de uma área mínima de $62,46 \mathrm{~m}^{2}$ de sala de aula (uma razão de $1,56 \mathrm{~m}^{2}$ por aluno);

De acordo com a NBR 9050:2015, em toda a instituição, no mínimo, uma a cada duas salas de aula deve ser acessível a cadeirantes, deste modo, a aplicação do MACHIA gerou as seguintes recomendações:

- O espaço de atividades do professor (compreendida entre a parte posterior do encosto da cadeira até a lousa) deve permitir a circulação e acesso de aluno em cadeira de rodas à lousa de ensino, com dimensão mínima de 0,90m;

- A área compreendida entre a parte frontal do tampo da mesa do professor e as primeiras carteiras deve permitir circulação e manobra de cadeira de rodas, com dimensão mínima de $1,20 \mathrm{~m}$;

Figura 9: Área mínima para atividades do professor.



Fonte: Elaborado pelo autor para a pesquisa. 




- ANBR 9050:2015 recomenda a dimensão mínima de 1,20m de largura para corredores de uso comum com extensão até 10,00m; e 1,50m para corredores com extensão superior a 10,00m. Estas dimensões se aplicam ao corredor entre a área de exposição da aula e a entrada da sala de aula e é suficiente para permitir o uso simultâneo de um cadeirante e uma pessoa adulta;

- O espaço com dimensão mínima de 1,20m X 0,80m deve ser disponibilizado próximo ao corredor de acesso, permitindo a acomodação de um aluno em cadeira de rodas;

- As dimensões definidas para espaços de movimentação aqui apresentadas e ilustradas, devem ser respeitadas quando da adoção de outros tipos de leiautes, preservando os deslocamentos com segurança e conforto.

Figura 10: Exemplo de corredor interno para acesso de aluno em cadeira de rodas.



Fonte: Elaborado pelo autor para a pesquisa.

- Ao se optar pelo tipo de leiaute de sala acessível com corredores laterais às carteiras, levando-se em consideração os espaços de circulação, dimensões das carteiras e área do professor (além da necessidade de comportar 40 alunos), deve-se dispor de uma área mínima de $77,36 \mathrm{~m}^{2}$ de sala de aula (uma razão de $1,93 \mathrm{~m}^{2}$ por aluno);

- Para corredores frontais e posteriores às carteiras, levando-se em consideração os mesmos critérios, deve-se dispor de uma área mínima de $75,68 \mathrm{~m}^{2}$ de sala de aula (uma razão de $1,9 \mathrm{~m}^{2}$ por aluno);

Com a aplicação do MACHIA, as recomendações ora apresentadas puderam ser estabelecidas. Tais parâmetros objetivaram o atendimento da adequação antropométrica da circulação do modelo e dimensão de sala de aula analisado e comprovaram que a dimensão da sala de aula não é suficiente para a quantidade de alunos a que se dispõe. 


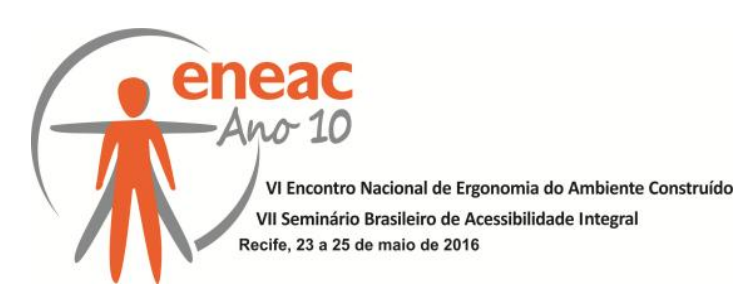

\section{CONCLUSÕES}

O estudo tornou evidente que a área de $35,00 \mathrm{~m}^{2}$ das salas de aula não atende aos requisitos normativos da instituição (Plano Diretor Físico: mínimo de 40m²), nem ao Código de Urbanismo, Obras e Posturas do Município de Caruaru (mínimo de $48 \mathrm{~m}^{2}$ ). O estudo revelou que seriam necessários um mínimo de $62,46 \mathrm{~m}^{2}$ (e razão de $1,56 \mathrm{~m}^{2}$ por aluno) para salas de aula não acessíveis; e um mínimo de $75,68 \mathrm{~m}^{2}$ (e razão $1,93 \mathrm{~m}^{2}$ por aluno) para salas de aula acessíveis. Desta forma, na melhor das hipóteses, a sala de aula deveria ter quase o dobro do tamanho para ter sua área dimensional adequada para comportar 40 alunos. Tais relações superam os valores apontados no Plano Diretor Físico da UFPE, que indica a relação máxima de 1 a $1,3 \mathrm{~m}^{2}$ por aluno para a menor área de sala considerada, assim como também superam a razão sugerida pelo Código de Obras da cidade de Caruaru, o qual sugere 1,2 a $1,5 \mathrm{~m}^{2}$ por aluno.

O leiaute das salas de aula, somado à quantidade de carteiras, tem configurado salas de aula de circulação antropometricamente inadequadas. Os estreitos corredores entre as carteiras também são responsáveis pelo desvio de atenção dos estudantes, os quais frequentemente precisam se afastar para permitir a circulação de alunos que entram ou saem da sala de aula. Outro ponto preocupante é a distância frontal e posterior entre as carteiras, a qual pode vir a contundir o aluno pela ausência de espaço para acomodação de seus membros inferiores (além da assunção de posturas de risco determinadas por esta ausência de espaço).

As inadequações antropométricas de circulação encontradas com a aplicação do MACHIA também podem vir a implicar em danos mais graves à saúde dos alunos. No intuito de evitar maiores transtornos ao pedir licença aos amigos para obter um espaço mínimo para circulação nos corredores de carteiras, alguns alunos podem vir a optar por não sair de sala, permanecendo em suas carteiras por todo o período de aula ( 3 horas de duração). A contenção de necessidades fisiológicas, tal como a urina, pode vir a causar danos à saúde, como por exemplo, a infecção urinária.

A triste constatação de tais níveis de inadequação antropométrica da circulação em sala de aula, bem como suas consequências para seus usuários, nos fazem perceber que atitudes simples como a redução de carteiras/alunos por sala e a relocação das turmas de 40 alunos para salas maiores poderia melhorar consideravelmente as condições de adequação dos usuários e de assimilação de conteúdos. As recomendações tecidas nesta pesquisa visam justamente a promoção da melhoria destes pontos de inadequação, uma vez que ficou comprovada a grande divergência dimensional entre a situação dimensional real do ambiente e a dimensão necessária para uma adequação antropométrica da circulação.

\section{REFERÊNCIAS}

ARENDS, R. Aprender a ensinar. 7. ed. Lisboa: McGraw-Hill, 2008. ASSOCIAÇÃO BRASILEIRA DE NORMAS TÉCNICAS. ABNT NBR 9050:2015 Acessibilidade a edifcações, mobiliário, espaços e equipamentos urbanos. ABNT, Rio de janeiro. 2015.

BARROS, Bruno. Avaliação Antropométrica de Espaços de Circulação Interna de Ambientes: um método proposto. In: CIPED 2009: Congresso Internacional de Pesquisa em Design, 2009, Bauru. Congresso Internacional de Pesquisa em Design (CIPED), 2009.

BARROS, Bruno; SEABRA FILHO, Sadi . MACHIA (método de avaliação da circulação


Congresso Internacional de Ergonomia e Usabilidade De Interfaces Humano-Tecnologia: 




Produto, Informações, Ambiente Construído e Transporte, 2013, Juiz de Fora. Anais do $13^{\circ}$ Ergodesign, 2013.

BOUERI FILHO, José Jorge. Espaço de atividades. Apostila de aula do Curso de Arquitetura e Urbanismo. São Paulo: Universidade de São Paulo, Faculdade de Arquitetura e Urbanismo - FAU, Departamento de Tecnologia e Arquitetura, 2009b.

CARVALHO, Valdemir Galvão de. Estudo ergonômico do Posto de Atividade Discente em Instituição de Ensino Superior. Dissertação de Mestrado - PPGEP/UFRN. Natal-RN, 2005.

GERRING, John. Case Study Research: principles and practices. $1^{\circ} \mathrm{Ed}$, Cambridge - Print On, 2006.

HAMMERSLEY, Martin; GOMM, Roger; FOSTER, Peter. Case Study Method: key issues, key texts. E-pub, Sage Publications Ed, 2014.

PANERO, J., ZELNIK, M. Dimensionamento Humano para Espaços Interiores. Gustavo Gili, Barcelona, 2013.

PREFEITURA MUNICIPAL DE CARUARU. Código de Urbanismo, Obras e Posturas do Município de Caruaru. Disponível em: http://camaracaruaru.pe.gov.br/2013/?page_id=3017. Acesso em: 17/06/2015.

PUCCI, Luis Fábio Simões. Sala Ambiente II: o espaço do Ensino Médio. Instituto Galileo Galilei para Educação. Copyright, 2001. Disponível em:

<http://www.geocites.com/researchtriangle/lab/6116/salaambientecronica.html>. Acesso em: 14 de fevereiro de 2014.

ROSENFIELD, Peter; LAMBERT, Nadine M.; BLACK, Allen. Desk arrangement effects on pupil classroom behavior. Journal of Educational Psychology, Vol 77(1), Feb 1985, 101-108.

UNIVERSIDADE FEDERAL DE PERNAMBUCO. Plano Diretor Físico da UFPE. Recife: Editora UFPE, 1985. 74p.

VILLAROUCO, V. (2007). O Ambiente Está Adequado? Anais do I Encontro nacional de ergonomia do ambiente construído, Recife-PE, 2007. 